\title{
Trends in sexual risk behavior, HIV knowledge and testing among reproductive-aged women in Nigeria: DHS 2003-2013
}

\author{
Chukwuma U. Okeafor ${ }^{1}$, Ibitein N. Okeafor ${ }^{2}$ \\ ${ }^{1}$ Department of Mental Health/Neuropsychiatry, University of Port Harcourt Teaching Hospital, Port Harcourt, Rivers State, Nigeria \\ ${ }^{2}$ Eagles Watch Research Centre and Care, Port Harcourt, Rivers State, Nigeria
}

\begin{abstract}
Introduction: Human immunodeficiency virus (HIV)/acquired immunodeficiency syndrome (AIDS) is the leading cause of deaths and disease among women of the reproductive age group (15-49 years) in low-income countries. It is therefore necessary to undertake periodic reviews of pertinent indices related to HIV/AIDS. This could serve as the basis for developing evidence-based strategies. The study is aimed to identify and monitor trends in sexual risk behaviors, HIV knowledge and testing among women of the reproductive age group in Nigeria.
\end{abstract}

Material and methods: Secondary data analysis of the Demographic Health Surveys (DHS) in Nigeria carried out from 2003 to 2013 was performed. Data on sexual risk behavior, HIV knowledge and testing among reproductive-aged women were extracted from the online log book to the Excel format. Chi square for trend was employed in the analysis using Epi Info version 7.

Results: The survey (2003-2013) had a total of 79,953 women aged 15-49 years. Mean age of respondents was $26.0 \pm 12$ years. Most of the respondents (71\%) were married or cohabiting. As to sexual risk behaviors, non-spousal sex and non-condom use showed a significant decline $(p<0.05)$. Although there was a $0.1 \%$ rise in multiple sex partnership, this trend was not statistically significant $(p>0.05)$. There were significant upward trends in the indicators of HIV knowledge and testing $(p<0.01)$.

Conclusions: Nigeria is making progress in the fight against HIV/AIDS among reproductive-aged women as reflected in the indicators on sexual risk behaviors, HIV knowledge and testing. However, collaboration with international stakeholders needs to be strengthened to enhance this progress.

HIV AIDS Rev 2017; 16, 2: 107-111

DOI: https://doi.org/10.5114/hivar.2017.66858

Key words: HIV testing, HIV knowledge, reproductive aged women, Nigeria Demographic and Health Surveys, sexual risk behaviors.

\section{Introduction}

The World Health Organization (WHO) estimates that 78 million people have been infected with the human immunodeficiency virus (HIV) and about 39 million people have died of HIV since the onset of the HIV epidemic [1]. Although the burden of this epidemic continues to vary between regions, sub-Saharan Africa remains most severely affected, with nearly 1 in every 20 adults living with HIV and accounting for nearly $71 \%$ of the people living with HIV worldwide [1].
Address for correspondence: Dr. Ibitein N. Okeafor, Eagles Watch Research Centre and Care, 107, East-West Road, 50001 Port Harcourt, Nigeria, phone: +2348069287279, e-mail: eagleswatchresearch@gmail.com
Article history:

Received: 31.10 .2016

Received in revised form: 08.12.2016

Accepted: 03.01.2017

Available online: 29.03.2017
International Journal of HIV-Related Problems

HIV \& AIDS

R e v i e w 
Reproductive-aged women living in low- and middleincome countries seem to be worst hit by the HIV epidemic [2]. In spite of the strategies on primary prevention of HIV/ AIDS among reproductive-aged women, this viral disease has been identified as the leading cause of deaths and disease among this category of women [2]. Noteworthy, in Nigeria, the HIV infection rate is two to three times higher in women than men [3]. The persistence of the HIV burden heralds the need for innovative strategies and policies to address such issues among this group of women who in most home fronts serve as the primary care givers [4].

It is well established that sexual risk behaviors propagate the spread of the HIV epidemic, with heterosexual transmission accounting for $80-90 \%$ of all infections [5]. However, paucity of knowledge on HIV transmission and prevention methods as well as absence of HIV testing in a populace could contribute to the further spread of the epidemic. This therefore highlights the need to explore HIV knowledge and testing, in addition to sexual risk behaviors among a population.

The Nigerian Demographic and Health Survey (DHS), which is a national probability sample survey serves as a veritable tool to identify and monitor the trends in sexual risk behaviors, HIV knowledge and testing. The first Nigerian DHS was carried out in 1990 [6], the second survey in 1999 [7] and the third one in 2003 [8]. After the third survey, DHS in Nigeria has been consistently carried out every 5 years [8-10]. Reviewing the trends of pertinent indices related to HIV/AIDS is necessary in identifying gaps in the country's war against the disease, assessing the changes over time and thus serves as the basis for evidence-based interventions. The research focused on women in the reproductive age group as this is vital for the development of evidence-based strategies targeted at curtailing the epidemic among them. This is further supported by the fact that the health of the reproductive-aged women is intricately linked to child and family survival.

Thus, this study is aimed to identify and monitor trends in sexual risk behaviors, HIV knowledge and testing among women in the reproductive age group in Nigeria using the 20032013 Nigeria DHS data.

\section{Material and methods}

\section{Site of study}

The study was conducted in all the six geopolitical zones of Nigeria. Nigeria is situated in West Africa and borders Benin, Niger, Chad, Cameroon and the Gulf of Guinea. Nigeria constitutes the most populous black nation, with an estimated population of 181,562,056 and a land mass area of 910,768 square kilometers [11].

\section{Study design}

This study was a secondary data analysis of Nigeria DHS carried out between 2003 and 2013. The DHS in Nigeria is a population-based household survey done every 5 years since 2003.

\section{Study population}

The study population is comprised of women aged 15 to 49 years who were respondents of the Nigeria DHS between 2003 and 2013.

\section{Sampling procedure}

A multi-stage probability sampling technique was employed to select children aged 0-5 years, women aged 15-49 years and men aged 15-59 years from the six geo-political zones (north-east, north-west, north-central, south-east, south-west, south-south) in Nigeria.

\section{Data management}

\section{Data collection}

The Nigerian DHS carried out from 2003 to 2013 was collected by the National Population Commission in conjunction with the ICF Macro Calverton, Maryland, USA [8-10]. The survey provides reliable data over a 5-year period on fertility and family planning behaviors, child mortality, children's nutritional status, the utilization of maternal and child health services, sexual risk behavior, knowledge, attitudes and practice of HIV/AIDS. The data on sexual risk behaviors, HIV knowledge and testing for women aged 15-49 years were extracted from the online log book to the Excel format. Data were weighted to adjust for disproportions in sampling prior to the analysis.

\section{Variables}

Socio-demographic variables of interest were age, marital status, education, residence (urban/rural), and region. The marital status was re-categorized as never married or married/living together or divorced/separated/widowed. Noteworthy, the educational level in Nigeria DHS refers to the educational level attained and not educational level completed.

The key variables examined in the analyses were indicators of sexual risk behaviors, HIV knowledge and testing. Indicators of sexual risk behaviors were multiple sex partnership (MSP), non-spousal sex and non-condom use among those engaged in multiple sex partnership and non-spousal sex. Multiple sex partnership was defined as having more than one sexual partner while sex with a non-marital, non-cohabiting partner was defined as non-spousal sex. Data on non-spousal sex were collected in 2003 and 2008 DHS while data on MSP were collected in 2008 and 2013 DHS.

HIV/AIDS knowledge was measured by three indicators namely knowledge on HIV prevention methods, knowledge on prevention of mother-to-child transmission and comprehensive knowledge of HIV/AIDS. The knowledge on HIV prevention was ascertained by respondents knowing that people can reduce the risk of being infected with the AIDS virus by using condoms every time they have sexual intercourse and by having one sex partner who is not infected and also has no other sexual partners. Knowledge of pre- 
vention of mother-to-child transmission was ascertained by respondents knowing that HIV can be transmitted from mother to child by breastfeeding and also knowing that the risk of mother-to-child transmission (MTCT) of HIV can be reduced by mother taking special drugs during pregnancy. Comprehensive knowledge on HIV/AIDS means knowing that consistent use of condoms during sexual intercourse; having just one HIV-negative faithful partner can reduce the chances of being infected with the AIDS virus; knowing that a healthy-looking person can have the AIDS virus; and rejecting the two most common local misconceptions about AIDS transmission and prevention (HIV cannot be transmitted by a mosquito bite or by sharing food with a person with AIDS). Data on comprehensive knowledge of HIV/AIDS were collected in 2008 and 2013 DHS. Data on HIV testing were based on two indicators of HIV testing, which were a proportion of respondents who have done an HIV test and a proportion of respondents who have never tested for HIV. HIV testing referred to those who were tested in the 12 months preceding the survey and received their test results. Never tested for HIV referred to those who have never done any HIV test at any point in time.

\section{Statistical analysis}

The Nigeria DHS data for this study are available online [12]. Statistical analysis was done using Epi Info Version 7. Trend Analysis was done using the $\chi^{2}$ for trend. Statistical significance was set at $p<0.05$.

\section{Ethical considerations}

The National Health Research Ethics Committee in Nigeria granted ethical approval for the surveys. Informed consent (verbal) was obtained from respondents before inclusion in the survey. Confidentiality was ensured in the surveys and anonymity was maintained by using numbers rather than names.

\section{Results}

\section{Demographic characteristics of study population}

The Nigeria DHS 2003, 2008 and 2013 had 7620, 33,385 and 38,948 women aged 15-49 years, respectively. This made an aggregate of 79,953 women aged $15-49$ years. The response rates were $95.4 \%, 96.5 \%$ and $97.6 \%$ for Nigeria DHS 2003, 2008 and 2013, respectively. Most of the respondents (38.0\%) were within the youth age category (15-24 years), were married/living together $(71.0 \%)$, had no education (37.3\%) and lived in rural areas (61.3\%). The demographic characteristics of study population are presented in Table 1.

\section{Trends in sexual risk behaviors}

The prevalence of MSP among reproductive-aged women increased from $1.0 \%$ in 2008 to $1.1 \%$ in 2013 . The prev-
Table 1. Demographic characteristics of the study population $(N=79,953)$

\begin{tabular}{|c|c|c|}
\hline Demographic variables & $n$ & $\%$ \\
\hline \multicolumn{3}{|l|}{ Age (years) } \\
\hline $15-19$ & 16029 & 20.0 \\
\hline $20-24$ & 14384 & 18.0 \\
\hline $25-29$ & 14836 & 18.6 \\
\hline $30-34$ & 11042 & 13.8 \\
\hline $35-39$ & 9446 & 11.8 \\
\hline $40-44$ & 7340 & 9.2 \\
\hline $45-49$ & 6877 & 8.6 \\
\hline Mean age \pm SD & \multicolumn{2}{|c|}{$26.0 \pm 9.5$} \\
\hline \multicolumn{3}{|l|}{ Marital status } \\
\hline Never married & 19649 & 24.6 \\
\hline Married/living together & 56744 & 71.0 \\
\hline Divorced/separated/widowed & 3561 & 4.4 \\
\hline \multicolumn{3}{|l|}{ Education } \\
\hline None & 29842 & 37.3 \\
\hline Primary & 14928 & 18.7 \\
\hline Secondary & 28201 & 35.3 \\
\hline Higher & 6983 & 8.7 \\
\hline \multicolumn{3}{|l|}{ Residence } \\
\hline Urban & 30977 & 38.7 \\
\hline Rural & 48976 & 61.3 \\
\hline \multicolumn{3}{|l|}{ Region } \\
\hline North central & 11441 & 14.3 \\
\hline North east & 11396 & 14.3 \\
\hline North west & 21994 & 27.5 \\
\hline South east & 9304 & 11.6 \\
\hline South south & 11757 & 14.7 \\
\hline South west & 14061 & 17.6 \\
\hline
\end{tabular}

alence of non-condom use among women who were engaged in MSP showed a statistically significant decrease $(p<0.05)$ from $77.2 \%$ in 2008 to $70.0 \%$ in 2013 . Non-spousal sex prevalence decreased from $10.9 \%$ in 2003 to $10.0 \%$ in 2008. Non-condom use among non-spousal sex partners had a significantly lower prevalence in 2008 than in 2003 survey period $(p<0.05)$ (Table 2$)$.

\section{Trends in HIV knowledge}

Knowledge on HIV prevention methods among the respondents showed a steady increase from $42.3 \%$ in 2003 , to $48.0 \%$ in 2008 and $54.4 \%$ in 2013 . Meanwhile the knowledge on prevention of mother-to-child transmission of HIV showed a markedly upward trend from $5.2 \%$ to $26.0 \%$ to $49.2 \%$ in the survey period of 2003-2013. Comprehensive 
Table 2. Sexual risk behavior indicators among women of reproductive age, Nigeria DHS 2003-2013

\begin{tabular}{l|c|c|c|c}
\hline Nigeria DHS & $\begin{array}{c}\text { MSP } \\
\%(n / N)\end{array}$ & $\begin{array}{c}\text { Non-condom use among MSP } \\
\%(n / N)\end{array}$ & $\begin{array}{c}\text { Non-spousal sex } \\
\%(n / N)\end{array}$ & $\begin{array}{c}\text { Non-condom use in non-spousal sex } \\
\%(n / N)\end{array}$ \\
\hline 2003 & - & - & $10.9(834 / 7620)$ & $76.7(640 / 834)$ \\
\hline 2008 & $1.0(346 / 33385)$ & $77.2(267 / 346)$ & $10.0(3344 / 33385)$ & $66.6(2226 / 3344)$ \\
\hline 2013 & $1.1(417 / 38948)$ & $70.0(292 / 417)$ & - & - \\
\hline$p$-value & 0.653 & $0.026^{*}$ & $0.016^{*}$ & $0.001^{*}$ \\
\hline
\end{tabular}

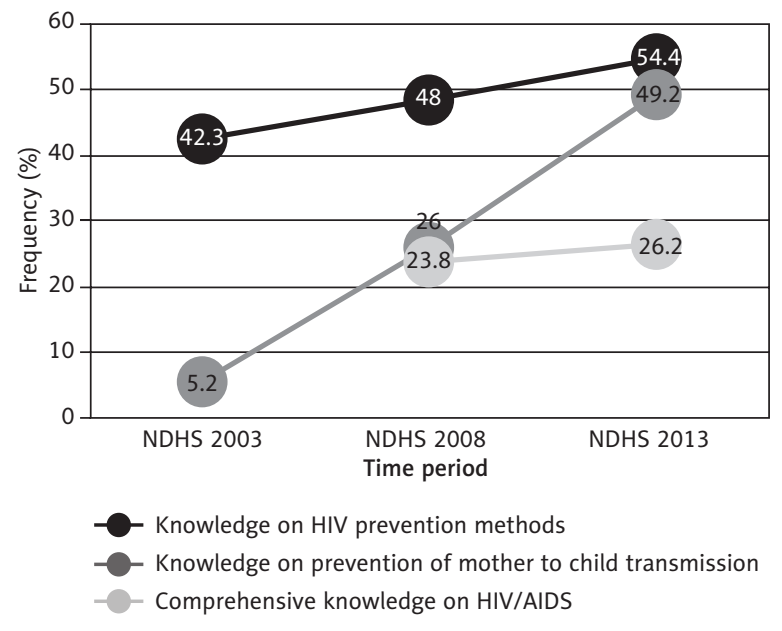

Figure 1. Trends in HIV knowledge indicators among women of reproductive age, Nigeria DHS 2003-2013; $p<0.01$ in all the three HIV knowledge indicators

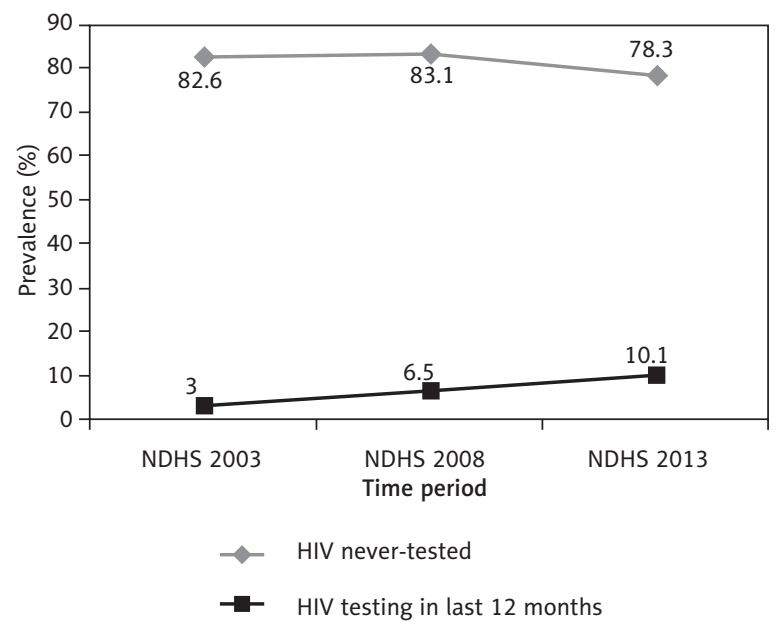

Figure 2. Trends in indicators of HIV testing among women of reproductive age, Nigeria DHS 2003-2013; $p<0.01$ in all two HIV testing indicators

knowledge on HIV/AIDS showed a marginal increase from $23.8 \%$ in 2008 to $26.2 \%$ in 2013 . The three HIV knowledge indicators showed a statistically significant upward trend $(p<0.01)$ over the time period. Figure 1 shows the trend in HIV knowledge indicators from 2003 to 2013.

\section{Trends in HIV testing}

The trend in HIV never-tested showed a slight decline from $82.6 \%$ in 2003 to $78.3 \%$ in 2013 . HIV testing in the last 12 months showed a steady increase from $3 \%$ to $6.5 \%$ to $10.1 \%$ from 2003 to 2013 (Figure 2). These trends noted in the HIV testing indicators were statistically significant $(p<0.01)$.

\section{Discussion}

The prevalence of sexual risk behaviors of women of reproductive age from this secondary data analysis reveals that in spite of the seemingly low prevalence of multiple sex partnership reported (1\%), more than half of the women engaged in MSP did not use condoms. This high prevalence of non-condom use amongst these women is a source of concern as they are at risk of being infected with HIV, having unwanted pregnancies and also having HIV-exposed babies if they become infected. This then highlights an urgent need to address this issue, more so, other studies have also noted high rates of non-condom use among women engaged in MSP [13-15]. The increase in MSP prevalence from Nigeria DHS 2008 to 2013, though not statistically significant, still heralds the call for interventions targeted at women of the reproductive age group. There is a general notion in African settings that women do not engage in MSP due to cultural beliefs [16], thus most intervention programs focus on men of the reproductive age. For the country to effectively curb the spread of HIV epidemic, which has been shown to have a devastating effect on reproductive-aged women, innovative programs on reducing risky sexual behaviors need to be launched while scaling up the current programs on HIV prevention among women.

As to knowledge on HIV, there was an increase in the trend from 2003 to 2013, which possibly reflects the widespread HIV awareness campaigns. Surprisingly, the increase in HIV knowledge over the time period did not translate to the adoption of the anticipated HIV preventive behaviors. This finding is similar to national demographic surveys carried out in Ghana [17] and Uganda [18], which similarly revealed an increase in the trend of HIV/AIDS knowledge in spite of risky behaviors. These findings along with the index study highlight the need to explore determinants of risky practices among reproductive-aged women in view of policy implications. The trend in the knowledge of prevention 
of mother-to-child transmission (PMTCT) of HIV infection from the 2003 to 2013 showed a doubled rate. This remarkable improvement in the knowledge of PMTCT of HIV across the time period is not surprising as several intervention programs both nationally and internationally have focused on PMTCT especially in rural areas of the country. Although this knowledge may not necessarily translate to the practice of PMTCT, it offers some hope that if current PMTCT programs are scaled up, the country can achieve the elimination of mother-to-child transmission of HIV.

The trend observed in HIV testing during survey period highlights the need to scale up the provision of HIV testing and counseling (HTC) services on a population-based scale. This is also vital to achieve the Joint United Nations Programme on AIDS (UNAIDS) global target of ensuring that $90 \%$ of people living with HIV/AIDS get tested and linked to care [19].

This secondary data analysis on the trends in the indicators on sexual risk behaviors, HIV knowledge and testing based on a national representative sample could serve as a reflection of the progress in the country's plan to combat the HIV epidemic among reproductive-aged women. It also identified the gaps in the performance as revealed by some of the indicators. However, the authors suggest further data analysis of the DHS to explore the correlates and predictors of some of these indicators.

\section{Conclusions}

The findings of this secondary data analysis show some significant progress in the HIV knowledge and testing indicators but these unfortunately have not translated to a significant reduction in sexual risk practices. Hence the need to reappraise the depth and scope of the interventions aimed at promoting safer sexual practices in women of the reproductive age and secure better health for this category of women who are saddled with the responsibility of bringing forth life.

\section{Conflict of interest}

The authors declared no potential conflicts of interest with respect to the research, authorship, and/or publication of this article.

\section{References}

1. World Health Organization. HIV/AIDS. Global Health Observatory (GHO), Geneva 2014.

2. Joint United Nations Programme on HIV/AIDS (UNAIDS). HIV/ AIDS Fact sheets. UNAIDS, 2014

3. National Agency for the Control of HIV/AIDS (NACA). Global AIDS Response: Nigeria Country Report 2012. Abuja, 2012.

4. Smith SL, Shiffman J. Setting the global health agenda: The influence of advocates and ideas on political priority for maternal and newborn survival. Soc Sci Med 2016; 166: 86-93.

5. Nasidi A, Harry TO. The epidemiology of HIV in Nigeria. In: AIDS in Nigeria: a Nation on the Threshold. Adeyi O, Kanki PJ, Odutolu O, Idoko JA (eds.). Harvard Center for Population and Development Studies, Cambridge 2006, pp. 37-130.
6. National Population Commission [Nigeria] and ORC Macro. Nigeria Demographic and Health Survey 1990. Nigeria 1991.

7. National Population Commission [Nigeria] and ORC Macro. Nigeria Demographic and Health Survey 1999. Nigeria 2000.

8. National Population Commission [Nigeria] and ORC Macro. Nigeria Demographic and Health Survey 2003. Nigeria 2004.

9. National Population Commission [Nigeria] and ICF Macro. Nigeria Demographic and Health Survey 2008. Nigeria 2009.

10. National Population Commission [Nigeria] and ORC Macro. Nigeria Demographic and Health Survey 2013. Nigeria 2014.

11. National Bureau of Statistics. Nigeria Population Census. Nigeria 2006.

12. The DHS Program - Quality information to plan, monitor and improve population, health, and nutrition programs. Available at: https://dhsprogram.com/. Accessed: 14 July 2014.

13. Noar SM, Webb E, Van Stee S, et al. Sexual partnerships, risk behaviors, and condom use among low-income heterosexual African Americans: a qualitative study. Arch Sex Behav 2012; 41: 959-970.

14. Lotfi R, Ramezani Tehrani F, Salehifar D, et al. Predictors of Condom Use Among Iranian Women at Risk of HIV. Arch Sex Behav 2016; 45: 429-437.

15. Zembe YZ, Townsend L, Thorson A, et al. Predictors of inconsistent condom use among a hard to reach population of young women with multiple sexual partners in peri-urban South Africa. PLoS One 2012; 7: e51998.

16. Ngubane SJ. Gender Roles in the African Culture: Implications for the spread of HIV/AIDS. Thesis MPhil (Industrial Psychology. Africa Centre for HIV/AIDS Management). University of Stellenbosch, Stellenbosch 2010

17. ICF and Ghana Ministry of Health. 2008 Ghana Demographic and Health Survey. Ghana 2008.

18. Uganda Bureau of Statistics and ICF. Uganda Demographic Health Survey 2012. Uganda 2012.

19. Joint United Nations Programme on HIV/AIDS (UNAIDS). 90-90-90 - An ambitious treatment target to help end the AIDS epidemic. UNAIDS 2014. Available at: http://www.unaids.org/en/resources/documents/2014/90-90-90. Acessed: 14 October 2016. 